\title{
AVALIAÇÃO DO NÍVEL TECNOLÓGICO DOS PRODUTORES DE LEITE NA REGIÃO OESTE DO ESTADO DO PARÁ ${ }^{1}$
}

\author{
Ana Laura dos Santos Sena ${ }^{2}$ \\ Marcos Antônio Souza dos Santos ${ }^{3}$ \\ Jair Carvalho dos Santos ${ }^{4}$ \\ Alfredo Kingo Oyama Homma
}

RESUMO: Este artigo apresenta um índice para avaliar o nível de desenvolvimento tecnológico da pecuária leiteira na região oeste do estado do Pará. Os dados foram obtidos de entrevistas com 176 produtores distribuídos entre os municípios de Itaituba, Rurópolis, Trairão e Placas. As variáveis representativas da adoção de tecnologias foram agregadas nos grupos: (i) instalações, máquinas e equipamentos; (ii) manejo reprodutivo; (iii) manejo sanitário; (iv) manejo de pastagens e suplementação alimentar; e (v) gestão e planejamento da produção. Posteriormente, foram submetidas à análise estatística para estimação do Índice de Desenvolvimento Tecnológico Global (IT). Os resultados indicaram que os municípios apresentavam baixo nível tecnológico, o que se refletia na baixa produtividade animal cuja média global foi de apenas 3,78 litros/vaca/dia. Nesse contexto, a implementação de políticas públicas que melhorem a infraestrutura de transportes e ampliem a oferta de crédito e dos serviços de assistência técnica e extensão rural é importante para estimular a adoção de tecnologias, visando a aumentar a produtividade e a gerar um produto de melhor qualidade.

Palavras-chave: Pecuária leiteira, Produtividade animal, Tecnologia, Estado do Pará.

1 Recebido em: 06/12/12. Aprovado em: 29/05/2013.

2 Economista; Doutora em Desenvolvimento Socioambiental; Pesquisadora da Embrapa Amazônia Oriental. E-mail: ana-laura.sena@embrapa.br

3 Engenheiro Agrônomo; Mestre em Economia; Professor da Universidade Federal Rural da Amazônia (UFRA). E-mail: marcos.santos@ufra.edu.br

4 Engenheiro Agrônomo; Doutor em Economia Rural; Pesquisador da Embrapa Amazônia Oriental. E-mail: jair.santos@embrapa.br

5 Engenheiro Agrônomo; Doutor em Economia Rural; Pesquisador da Embrapa Amazônia Oriental. E-mail: alfredo.homma@embrapa.br 


\begin{abstract}
The objective was to estimate an index for measuring the level of technological development of dairy farming in Western of Pará State. Data were obtained from the survey of 176 producers distributed in the municipalities of Itaituba, Rurópolis, Trairão and Placas. The variables representing the adoption of technologies have been pooled into the following groups: (i) plant, machinery and equipment, (ii) reproductive management, (iii) health management, (iv) pasture management and supplementary feeding, and (v) management and production planning, and, subsequently, subjected to statistical analysis to estimate a Global Technological Development Index (IT). The results indicated that the municipalities had low technological level which is reflected in low animal productivity whose overall average was only 3.78 liters/cow/day. In this context, the implementation of public policies to improve transport infrastructure and expand the supply of credit and technical assistance are important factors to stimulate the adoption of technologies to increase productivity and generate a product of higher quality.
\end{abstract}

Keywords: Dairy farming, Animal productivity, Technology, State of Pará.

\title{
1. Introdução
}

A partir de 1990, as mudanças ocorridas na cadeia do leite no Brasil tiveram impacto direto sobre o número de produtores que continuaram a desenvolver a pecuária leiteira no país. Uma parte deles conseguiu se adaptar e continuou no setor, o que explica a presença de produtores que possuem uma estrutura de produção com um nível tecnológico mais elevado e que produzem leite de alta qualidade; outra parte não conseguiu se adequar às transformações no mercado e terminou abandonando a atividade; e, por fim, uma parcela continuou desenvolvendo a pecuária de leite, mas de uma maneira informal.

No caso da pecuária leiteira desenvolvida na Amazônia, essa situação de heterogeneidade entre os produtores é acentuada em razão de a pecuária de leite ser desenvolvida em grande parte por pequenos produtores (SENA et al., 2010).

Em uma mesma região, podem ser encontrados sistemas de produção de leite muito heterogêneos (VENEGAS, 2007). Essa heterogeneidade 
dos sistemas está relacionada às condições locais em que se desenvolve a produção leiteira. Especificidades econômicas, sociais, políticas e ambientais vão influenciar em sua estruturação, e sistemas produtivos mais eficientes em uma região podem não ser os mais eficientes em outras áreas. Nesse contexto, Poccard-Chapuis et al. (2003) chamam a atenção para o fato de, muitas vezes, os problemas com a qualidade do leite serem decorrentes de fatores que podem ser modificados por ações simples, que não exigem muitos recursos ou tecnologia sofisticada.

Com base nesse contexto, este artigo objetiva avaliar o nível tecnológico dos produtores de leite nos municípios de Itaituba, Trairão, Rurópolis e Placas, no estado do Pará.

\section{Pecuária leiteira na região norte e no estado do Pará}

Na produção de leite, segundo dados da Pesquisa Pecuária Municipal (PPM), as regiões sudeste e sul são responsáveis pela maior parcela do leite produzido no país. No ano de 2011, a região Sudeste produziu 11.308.133 mil litros de leite, com a região Sul registrando o segundo lugar, com 10.229.801 mil litros. As regiões Centro-Oeste, Nordeste e Norte produziram, respectivamente, 4.777 .064 mil litros, 4.100 .729 mil litros, e 1.675.283 mil litros (IBGE, 2012).

A região Norte, apesar de ter respondido por apenas $5,2 \%$ da produção nacional, em 2011, vem apresentando taxas elevadas de crescimento. Entre 1990 e 2011, exibiu a maior taxa de aumento da produção, 6,2\% ao ano, contra um crescimento agregado de $3,8 \%$ ao ano para o Brasil. Rondônia e Pará são os maiores produtores regionais. Em 2011, foram responsáveis por $42,2 \%$ e $35,3 \%$ do total produzido, respectivamente. Esses estados também vêm exibindo crescimento significativo da produção com taxas de crescimento de 7,8\% e 5,7\% ao ano, respectivamente (IBGE, 2012).

A pecuária leiteira na região Norte é desenvolvida, em grande parte, em pequenas propriedades familiares, que apresentam, em geral, baixo nível 
tecnológico. Em razão disso, a análise desse sistema de produção deve levar em consideração as especificidades da agricultura familiar, pois o sistema de criação é extensivo, com a pastagem sendo a principal fonte alimentícia dos rebanhos. A manutenção de rebanhos com dupla aptidão por parte dos pequenos produtores de leite faz parte da estratégia de diversificação da composição da renda, em que a comercialização regular do leite é complementada com a venda de bezerros para produtores de gado de corte, situação que limita uma maior especialização e, consequentemente, tem reflexos sobre a produtividade. Aliado a isso, em muitos locais, ainda persistem problemas de infraestrutura de energia elétrica e rodoviária, dificultando a conservação do leite cru nas propriedades e seu transporte até os laticínios.

SENA et al. (2010) conduziram estudo sobre a concentração espacial da produção leiteira no estado do Pará e avaliaram aspectos relacionados à estrutura produtiva da atividade no período 1990-2008. Os autores identificaram que o crescimento de $6,88 \%$ ao ano na produção ocorreu em função dos ganhos de produtividade animal, cuja taxa de crescimento foi de 4,36\% ao ano, superando a expansão do plantel de vacas ordenhadas, que foi de $2,42 \%$ ao ano. No estado do Pará, houve crescimento significativo na produção de leite nas mesorregiões Baixo Amazonas, Sudeste Paraense e Sudoeste Paraense, onde o efeito produtividade foi superior ao efeito expansão do rebanho. Contudo, apesar de a produtividade ainda ser baixa, observa-se grande diferenciação nesse quesito entre os municípios paraenses, com a produtividade média variando de 135,03 a 701,42 litros/vaca/ano.

No Pará, a produção de leite tem decrescido desde 2005 e a queda só não foi mais significativa em função do crescimento da produtividade observado neste período. Esse movimento de diminuição da produção total apresentou inversão em 2011, mas sem voltar a alcançar o nível registrado em 2005. Essa situação expõe a necessidade de buscar alternativas para que a produção de leite retome uma trajetória ascendente no Estado, uma vez que esses produtores estão inseridos em um mercado cada vez mais competitivo e exigente em termos de qualidade da matéria- 
prima. Ações que busquem fortalecer os laticínios já existentes e atrair novos são também de grande importância para o fortalecimento da cadeia como um todo. Dessa forma, buscou-se avaliar o nível tecnológico dos municípios de Itaituba, Trairão, Rurópolis e Placas, por constituírem municípios com potencial para a formação de uma bacia leiteira no Oeste do estado do Pará.

\section{Metodologia}

Os dados apresentados neste trabalho compõem o projeto de pesquisa "Diagnóstico e caracterização da cadeia produtiva leiteira na região Oeste do Pará", financiado pelo Serviço Brasileiro de Apoio às Micro e Pequenas Empresas do Pará (Sebrae-PA), e foram obtidos pela aplicação 176 questionários distribuídos entre produtores dos municípios de Itaituba, Rurópolis, Trairão e Placas, localizados na região Oeste do estado do Pará (SANTOS et al., 2010). A amostra representa, para o conjunto dos quatro municípios, $22,98 \%$ do número de estabelecimentos agropecuários que produziam leite, de acordo com os dados do Censo Agropecuário de 2006, em que foram identificadas 766 unidades produtoras de leite (IBGE, 2010). A definição das propriedades que seriam visitadas para a realização das entrevistas foi feita de forma aleatória, através de reuniões com técnicos lotados nos municípios pesquisados, do Serviço Brasileiro de Apoio às Micro e Pequenas Empresas no Estado do Pará (Sebrae/PA), da Empresa de Assistência Técnica e Extensão Rural do Estado do Pará (Emater/PA) e das secretarias municipais de agricultura para a obtenção de informações sobre a localização das áreas produtoras de leite.

O levantamento de dados primários foi realizado no período de 30 de novembro a 11 de dezembro de 2009. As entrevistas foram feitas com os proprietários das áreas ou com as pessoas encarregadas diretamente da administração das propriedades quando o proprietário estava ausente. Essas informações foram analisadas no programa Statistical Package for the Social Sciences (SPSS), versão 17.0. 
Em relação às variáveis utilizadas para a construção do Índice de Desenvolvimento Tecnológico Global (IT), a seleção foi baseada nas características da situação atual da pecuária leiteira na região amazônica e na sua importância para o aumento da eficiência produtiva e socioeconômica. Os 176 produtores entrevistados ficaram assim distribuídos: Placas, 67 produtores (38,07\%); Itaituba, 44 produtores $(25,00 \%)$; Rurópolis, 36 produtores $(20,45 \%)$; e Trairão, 29 produtores $(16,48 \%)$.

As variáveis foram reunidas em cinco grupos, representando cada um deles uma tecnologia. Para cada uma das tecnologias, foi constituído um Índice Tecnológico Parcial (IP):

a) Tecnologia 1 ( $\left.\mathrm{IP}_{1}\right)$ : Instalações, Máquinas e Equipamentos;

b) Tecnologia 2 ( $\left.\mathrm{IP}_{2}\right)$ : Manejo Reprodutivo;

c) Tecnologia $3\left(\mathrm{IP}_{3}\right)$ : Manejo Sanitário;

d) Tecnologia $4\left(\mathrm{IP}_{4}\right)$ : Manejo de Pastagens e Suplementação Alimentar; e

e) Tecnologia 5 ( IP $\left._{5}\right)$ : Gestão e Planejamento da Produção.

Para cada variável, foi atribuído um escore, tendo como base aquelas consideradas mais adequadas para melhorar a eficiência produtiva nas propriedades. O cálculo do nível tecnológico final foi efetuado com base nas cinco tecnologias que, em conjunto, formam o Índice de Desenvolvimento Tecnológico Global (IT), que é definido para cada município.

Também foram incluídas na determinação do $\mathrm{IP}_{5}$ duas variáveis que não estão relacionadas diretamente com as práticas de produção, mas que têm importante influência no desenvolvimento das ações dos produtores, especialmente aquelas ligadas à adoção de tecnologias no processo 
produtivo. Essas variáveis foram os anos de estudo dos produtores e sua experiência no desenvolvimento da pecuária leiteira. As variáveis que compõem cada uma das tecnologias estão listadas na Tabela A1, em anexo.

O índice tecnológico foi determinado conforme especificado em Araújo et al. (2008), Oliveira (2003) e Freitas (2003).

a) Determinação do Índice Tecnológico $I$ do produtor $j$ relativo à tecnologia $t$

$$
I_{j t}=\sum_{i=1}^{z} \frac{a_{i}}{w_{t}}
$$

Sendo:

$w_{t}=\max \sum_{i=1}^{z} a_{i}$ e, dessa forma, $0 \leq I_{j t} \leq 1$

$a_{i}$ é o escore da adoção da variável $X_{i}$ na tecnologia $t$

Assim, $\frac{a_{i}}{w_{t}}$ representa o peso de cada elemento $a_{i}$ na formação do índice tecnológico $I$ específico.

Dessa forma:

Para a tecnologia Instalações, Máquinas e Equipamentos $\left(I_{t 1}\right), \mathrm{t}=1$; $\mathrm{i}=[1 ; 17]$ e $\mathrm{w}=25$;

Para a tecnologia Manejo Reprodutivo $\left(I_{t 2}\right), \mathrm{t}=2 ; \mathrm{i}=[18 ; 24]$ e w=14; 
Para a tecnologia Manejo Sanitário $\left(I_{t 3}\right), \mathrm{t}=3 ; \mathrm{i}=[25 ; 31]$ e w=12;

Para a tecnologia Manejo de Pastagens e Suplementação Alimentar ( $I_{t 4}$ ), $\mathrm{t}=4 ; \mathrm{i}=[32 ; 41]$ e $\mathrm{w}=20$; e

Para a tecnologia Gerenciamento e Planejamento da Produção $\left(I_{t 5}\right)$, $\mathrm{t}=5 ; \mathrm{i}=[42 ; 51]$ e $\mathrm{w}=20$.

Em que:

$I=$ Índice Tecnológico;

$I_{j}=$ Índice geral para cada produtor envolvendo todas as tecnologias;

$I_{j t}=$ Índice Tecnológico $I$ do produtor $j$ relativo à tecnologia $t$

$j=$ Produtores $(j=1,2 \ldots \ldots \ldots n)$;

$n=$ Número de produtores;

$t=$ Tecnologias utilizadas $(t=1,2,3,4,5)$;

$m=$ Número de tecnologias $(m=5)$;

IP = Índice Tecnológico Parcial; e

IT = Índice de Desenvolvimento Tecnológico Global.

b) Índice Tecnológico Parcial $(I P)$ dos produtores em relação à tecnologia $t$ 
$\mathrm{IP}=\frac{1}{n} \sum_{j=1}^{n} I$

c) Índice de Desenvolvimento Tecnológico Global (IT) dos produtores pesquisados

$\mathrm{IT}=\frac{1}{m} \sum_{j=1}^{m} P$

d) Padrões tecnológicos

Se $0,75<I T \leq 1$, os produtores apresentam nível I de tecnologia; nível tecnológico alto;

Se $0,50<I T \leq 0,75$, os produtores apresentam nível II de tecnologia; nível tecnológico médio;

Se $0,25<I T \leq 0,50$, os produtores apresentam nível III de tecnologia; nível tecnológico baixo; e

Se $0<I T \leq 0,25$, os produtores apresentam nível IV de tecnologia; nível tecnológico muito baixo.

\section{Resultados e discussão}

A observação dos índices tecnológicos parciais (Tabela 1) mostrou que os municípios apresentam baixo nível tecnológico. Em relação ao $\mathrm{IP}_{1}$ (Instalações, Máquinas e Equipamentos), Rurópolis foi o município que apresentou maior pontuação $(0,47)$, vindo, em seguida, Itaituba $(0,40) \mathrm{e}$ Trairão $(0,39)$, com percentuais muito próximos, e Placas com a menor pontuação $(0,34)$. Na análise do $\mathrm{IP}_{2}$ (Manejo Reprodutivo), o município de Itaituba surgiu com maior pontuação $(0,37)$, com Rurópolis e Trairão apresentando valores iguais de 0,32 , ficando novamente Placas na última 
posição (0,27). Em relação ao IP3 (Manejo Sanitário), Itaituba, Rurópolis e Placas foram os municípios com maior pontuação, respectivamente, 0,$41 ; 0,40$ e 0,39, com Trairão registrando um valor bem menor nesse quesito em relação aos municípios estudados $(0,31)$. No cálculo do $\mathrm{IP}_{4}$ (Manejo de Pastagens e Suplementação Alimentar), Itaituba também ficou com maior pontuação $(0,42)$, Rurópolis apresentou um resultado muito próximo $(0,41)$, sinalizando maior preocupação dos produtores desses municípios com o problema de degradação das pastagens; Trairão e Placas registraram os menores resultados, 0,34 e 0,33, respectivamente, para o $\mathrm{IP}_{4}$. Quanto ao $\mathrm{IP}_{5}$ (Gestão e Planejamento da Produção), Itaituba $(0,36)$, Rurópolis $(0,35)$ e Trairão $(0,35)$ surgiram com resultados muito próximos, ficando Placas novamente com o menor índice $(0,32)$.

Tabela 1 - Índices Tecnológicos Parciais e Índice de Desenvolvimento Tecnológico Global dos produtores, de acordo com o município, 2009.

\begin{tabular}{lcccccc}
\hline Município & $\mathrm{IP}_{1}$ & $\mathrm{IP}_{2}$ & $\mathrm{IP}_{3}$ & $\mathrm{IP}_{4}$ & $\mathrm{IP}_{5}$ & $\mathrm{IT}$ \\
\hline Itaituba & 0,40 & 0,37 & 0,41 & 0,42 & 0,36 & 0,39 \\
Placas & 0,34 & 0,27 & 0,39 & 0,33 & 0,32 & 0,33 \\
Rurópolis & 0,47 & 0,32 & 0,40 & 0,41 & 0,35 & 0,39 \\
Trairão & 0,39 & 0,32 & 0,31 & 0,34 & 0,35 & 0,34 \\
Total & 0,39 & 0,31 & 0,38 & 0,37 & 0,34 & 0,36 \\
\hline
\end{tabular}

Fonte: Pesquisa de campo.

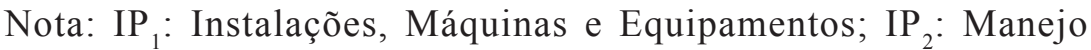
Reprodutivo; $\mathrm{IP}_{3}$ : Manejo Sanitário; $\mathrm{IP}_{4}$ : Manejo de Pastagens e Suplementação Alimentar; $\mathrm{IP}_{5}$ : Gestão e Planejamento da Produção; e IT: Índice de Desenvolvimento Tecnológico Global.

No município de Itaituba, deve-se destacar que existe um efeito importante da pecuária de corte praticada por produtores com maior poder aquisitivo, como comerciantes e garimpeiros, no desenvolvimento 
das atividades ligadas à pecuária leiteira, que poderia ter influenciado a maior participação que o IP $\mathrm{IP}_{3}$ e IP $\mathrm{IP}_{4}$ tiveram na composição do IT, pois a pecuária leiteira passou a utilizar uma parte da infraestrutura construída para a pecuária de corte, bem como das práticas de manejo sanitário, pastagens e alimentar. No que se refere ao $\mathrm{IP}_{4}$, esse resultado pode estar relacionado ao fato de o município ser uma área de colonização mais antiga, apresentando, portanto, solos mais degradados, o que exige maior atenção para o manejo de pastagens e alimentação do rebanho.

Em relação a Placas, o IP 3 obteve maior destaque. Esses dados indicaram que, nesse município, os produtores estavam direcionando mais cuidados para o manejo sanitário do rebanho, devendo-se também destacar que as áreas de maior produção de leite estavam também localizadas em solos de maior fertilidade (nitrossolo vermelho). Por outro lado, ficaram claras as dificuldades mais intensas no manejo reprodutivo nesse município, e uma das causas poderia estar relacionada à predominância de um rebanho misto usado na produção de leite, mas que ainda pareciam ser compensadas pelas melhores condições das pastagens. Dessa forma, em Placas, verificou-se a necessidade de apoio para melhorar a infraestrutura para a pecuária leiteira, uma vez que o município registrou os menores valores para a maior parte dos IPs, com exceção do $\mathrm{IP}_{3}$. Os baixos valores dos IPs de Placas, contrastados com seus níveis de produtividade, mostraram que o município tinha grande potencial de aumento na produtividade, na medida em que as condições de infraestrutura, crédito e apoio técnico forem mais bem acessadas pelos produtores.

Rurópolis foi o município que recebeu apoio governamental mais intenso, tendo a cooperativa de produtores de leite do município obtido recursos para a melhoria das instalações do laticínio através da Secretaria de Agricultura do Estado do Pará (SAGRI), e o SEBRAE-PA efetuado ações ligadas à assessoria técnica aos produtores e ao laticínio da cooperativa. Além disso, a cooperativa contou com apoio não governamental, recursos de uma igreja evangélica que ajudaram no processo de construção do laticínio. Em relação à maior participação do $\mathrm{IP}_{1}$ no IT, para este município originário da colonização da Transamazônica, ao contrário de Itaituba, a importância da pecuária leiteira para a economia local era 
maior, o que pode ter estimulado o direcionamento da infraestrutura produtiva existente por parte dos produtores para a atividade ligada ao leite. Um ponto a chamar a atenção estava ligado à participação do $\mathrm{IP}_{4}$, que poderia estar relacionado aos solos mais degradados desse município, em razão dos anos de exploração, o que exigia dos produtores maior atenção para o manejo de pastagens e suplementação alimentar do rebanho, novamente de forma semelhante a Itaituba.

O município de Trairão abrangia áreas de colonização mais novas, com pastos menos degradados, em que havia um predomínio de vacas de raças leiteiras na constituição dos rebanhos para a pecuária de leite. Nesse município, o IP 1 alcançou o maior valor, seguido pelo $\mathrm{IP}_{5}$. Os resultados do $\mathrm{IP}_{1}$ poderiam estar ligados aos efeitos dos financiamentos recebidos pelos produtores para investimento, já no que se refere ao $\mathrm{IP}_{5}$, a maior parte dos produtores de leite vinha de regiões com tradição no desenvolvimento da atividade, o que pode ter influenciando um melhor gerenciamento da produção.

Em geral, na região em estudo, pôde ser verificado que a tecnologia relativa a Instalações, Máquinas e Equipamentos $\left(\mathrm{IP}_{1}\right)$ era a que apresentava maior proporção de utilização $(0,39)$, vindo, em segundo lugar, a tecnologia Manejo Sanitário ( $\left.\mathrm{IP}_{3}\right)$, com 0,38. No outro extremo, encontrava-se a tecnologia Manejo Reprodutivo $\left(\mathrm{IP}_{2}\right)$, com menor utilização $(0,31)$, em relação ao valor alcançado pelo $\mathrm{IP}_{2}$. A transição da pecuária de corte para a pecuária de leite em alguns dos municípios estudados e os riscos relacionados aos laticínios em outros podem ter influenciado no menor valor do $\mathrm{IP}_{2}$. Esses resultados mostraram a possibilidade de os produtores estarem enfrentando mais dificuldades nesses itens e a necessidade de medidas de políticas públicas e orientação técnica visando a contornar tais deficiências. Uma das ações poderia estar relacionada ao financiamento para custeio, pois até o momento de realização desta pesquisa, os financiamentos tinham sido prioritariamente para investimento. 
No cálculo do IT, os municípios de Rurópolis e Itaituba apresentaram a maior pontuação $(0,39)$, ficando em segundo e terceiro lugares, respectivamente, Trairão $(0,34)$ e Placas $(0,33)$. Verificou-se, assim, que os municípios de ocupação pecuária mais antiga (Itaituba e Rurópolis) registraram nível tecnológico um pouco mais alto comparativamente aos de ocupação pecuária mais recente (Placas e Trairão), embora, em termos de produtividade, Placas e Trairão tenham apresentado resultados um pouco melhores. Isto pode indicar que fatores naturais, como solos menos degradados, podem estar influenciando esses resultados em razão do baixo nível tecnológico do grupo de municípios em estudo.

Nesse contexto, observou-se que, em geral, do conjunto de tecnologias indicadas para a pecuária leiteira para compor o IT, em Rurópolis e Itaituba, eram utilizadas 39\% delas, em Trairão 34\% e em Placas 33\%. Merece destaque o fato de nenhum município ter conseguido alcançar pelo menos a metade da pontuação do IT, o que confirmou um nível tecnológico geral baixo para a região em estudo, que utilizou, em média, $36 \%$ do conjunto de tecnologias indicadas. Entretanto, apesar de a maior parte dos criadores terem apresentado um nível tecnológico baixo, o que se reflete nos índices gerais dos municípios, deve ser ressaltada a presença de um pequeno grupo de produtores que alcançou um nível tecnológico mais alto, com percentuais de utilização acima de 50\% das tecnologias analisadas.

Em Itaituba ocorria algum comércio informal da produção de leite, pois os produtores não tinham para quem vender seu produto. Nesse município, existia um laticínio pequeno, mas que processava apenas a produção de leite proveniente da propriedade do proprietário do laticínio. Essa situação desestimulava os criadores a aumentar a produção, refletindo-se também negativamente na adoção de mudanças tecnológicas no processo produtivo. Em Rurópolis, o laticínio já estava mais estruturado, diminuindo o risco dos produtores, o que era um fator de estímulo para implantação de novas tecnologias na produção de leite. Em Trairão, a presença de um laticínio vinha influenciando positivamente o desenvolvimento da atividade, embora problemas de relacionamento 
comercial, entre o laticínio e os produtores de leite, precisassem ainda ser contornados. Em Placas, apesar de existirem dois laticínios, eles ainda não estavam legalmente formalizados, o que causava insegurança aos produtores. Essa situação repercutia no direcionamento de recursos para investir na produção de leite, trazendo dificuldades para adoção de novas tecnologias por parte dos produtores para a atividade.

A análise do nível tecnológico dos produtores individualmente (Tabela 2) revelou que nenhum deles conseguiu alcançar o nível I de tecnologia, com a maioria sendo classificada no nível III. Para todos os municípios, a média dos produtores também ficou no nível tecnológico III.

Tabela 2 - Classificação do nível tecnológico alcançado pelos produtores de leite, Oeste Paraense - 2009.

\begin{tabular}{cccccc}
\hline $\begin{array}{c}\text { Nível } \\
\text { Tecnológico }\end{array}$ & $\begin{array}{c}\mathrm{N}^{\circ} \text { de } \\
\text { produtores }\end{array}$ & \% produtores & Mínimo & Média & Máximo \\
\hline II & 15 & 8,52 & 0,50 & 0,58 & 0,71 \\
III & 144 & 81,82 & 0,25 & 0,35 & 0,49 \\
IV & 17 & 9,66 & 0,13 & 0,22 & 0,24 \\
Total & 176 & 100,00 & 0,13 & 0,36 & 0,71 \\
\hline
\end{tabular}

Fonte: Pesquisa de campo.

Entre os criadores classificados no nível tecnológico II (melhores resultados), não existia a concentração em um município específico. Os 15 produtores desta classe ficaram assim distribuídos: três encontravam-se em Itaituba; três, em Placas; cinco, em Rurópolis; e quatro, em Trairão. No contexto dos municípios em estudo, esses produtores poderiam, inicialmente, ser tomados como referência para os produtores, em geral, na busca da melhora tecnológica.

No exame da produtividade (Tabela 3), observou-se que no nível II a média de produção diária por vaca era de 5,07 litros, mostrando que os produtores que detinham maior padrão tecnológico eram mais produtivos 
que os demais. A análise dos níveis III e IV mostrou que a diferença de produtividade entre eles era muito reduzida, o que provavelmente estava relacionado à média do IT alcançada pelos criadores do nível IV $(0,22)$, que estava próxima ao valor mínimo do nível tecnológico III, de 0,25 (Tabela 2).

Tabela 3 - Produtividade (litros/vaca/dia), de acordo com o nível tecnológico, Oeste Paraense - 2009.

\begin{tabular}{ll}
\hline Nível Tecnológico & Média (litros/vaca/dia) \\
\hline II & $5,07^{\mathrm{a}}$ \\
III & $3,66^{\mathrm{b}}$ \\
IV & $3,61^{\mathrm{bc}}$ \\
Média global & 3,78 \\
\hline
\end{tabular}

Fonte: Pesquisa de campo.

Nota: Médias seguidas de letras iguais não diferem estatisticamente ao nível de $5 \%$ pelo Teste de Tukey.

O exame do tempo de experiência dos produtores no desenvolvimento da atividade leiteira revelou que os que estavam no nível II já trabalhavam, em média, 20 anos, com a produção de leite; para os produtores do nível III, a média de experiência na atividade estava em torno de 13 anos; e, no nível IV, oito anos. Esses resultados sinalizaram que a experiência tinha impacto na adoção de mudanças tecnológicas na produção, especialmente em uma área em que os produtores enfrentam sérios problemas de acesso à assistência técnica, embora os resultados do IT em geral tenham sido baixos. Em relação ao tempo de estudo, os produtores do nível II também apresentaram escolaridade maior, 7,4 anos de estudo, quando comparados aos dos níveis III, 5,7 anos, e nível IV, 4,1 anos. 


\section{Conclusões}

Os resultados indicam que, embora tenham sido identificados produtores mais tecnificados e especializados na produção de leite, nos municípios de Itaituba, Rurópolis, Trairão e Placas, a maioria ainda se encontrava em um nível tecnológico baixo, sendo que nesse conjunto havia uma parcela de produtores que poderia vir a se especializar na pecuária leiteira e outra que talvez ainda preferisse continuar desenvolvendo a pecuária mista. A tomada de decisão pelos produtores entre os vários caminhos existentes envolvia a análise das alternativas de produção agropecuária presentes nos municípios e os riscos associados a cada uma delas.

Entre os fatores que podem influenciar a adoção de novas tecnologias pelos produtores de leite na região, podem ser destacadas: as condições de mercado relacionadas ao comportamento da demanda de leite e derivados em termos de quantidade e qualidade; as exigências legais quanto à produção do leite cru; a concorrência de produtos de outras regiões; a possibilidade de instalação de novos laticínios e melhor estruturação dos laticínios já existentes; as questões ambientais, especialmente aquelas ligadas à degradação das pastagens; a melhoria na infraestrutura das estradas e de energia elétrica; e a conscientização dos próprios criadores sobre os benefícios que a adoção de novas práticas tecnológicas pode trazer.

\section{Referências}

ARAÚJO, A.C.; KHAN, A.S.; SILVA, L.M.R.; ARAÚJO, L.V. Índice tecnológico e sazonalidade do maracujá no extremo sul da Bahia. In: Congresso Brasileiro da Sociedade de Economia, Administração e Sociologia Rural - SOBER, 2008, Acre. Anais ... Acre: SOBER, 2008, p.1-16.

FREITAS, D.G.F. Nível tecnológico e competitividade da produção de mel de abelhas (Apis mellifera) no Ceará. 2003. 109 p. Dissertação 
(Mestrado em Economia Rural). Universidade federal do Ceará, Fortaleza, 2003.

INSTITUTO BRASILEIRO DE GEOGRAFIA E ESTATÍSTICA. Censo Agropecuário. Disponível em: http://www.ibge.gov.br. Acesso em 13 set. de 2010 .

INSTITUTO BRASILEIRO DE GEOGRAFIA E ESTATÍSTICA. Pesquisa Pecuária Municipal. Disponível em: http://www.ibge.gov. br. Acesso em: 21 jun. 2012.

OLIVEIRA, M.A.S. Nível tecnológico e seus fatores condicionantes na bananicultura no município de Mauriti-CE. 2003. $107 \mathrm{f}$. Dissertação (Mestrado em Economia Rural). Centro de Ciências Agrárias. Departamento de Economia Agrícola - Universidade Federal do Ceará, Fortaleza, 2003.

POCCARD-CHAPUIS, R.; VEIGA, J.B.; VIEIRA, L.C.; FREITAS, C.M.K.H.; PIKETTY, M.G.; TOURRAND, J. Organização e consolidação da cadeia produtiva do leite na Zona Bragantina. Belém: Embrapa Amazônia Oriental, 2003 (Documentos, 135).

SANTOS, J.C.; ROSSETO, A.G.; RODRIGUES FILHO, J.A.; SENA, A.L.S.; QUINZEIRO NETO, T.; SANTOS, M.A.S.; MATOS, HOMMA; A.K.O. Diagnóstico e caracterização da cadeia produtiva leiteira na Região Oeste do Pará. Belém: Embrapa Amazônia Oriental, 2010 (Relatório de Pesquisa).

SENA, A.L.S.; SANTOS, M.A.S. SANTOS, J.C.; HOMMA, A.K.O. Concentração espacial e caracterização da pecuária leiteira no Estado do Pará. In: $48^{\circ}$ Congresso da Sociedade Brasileira de Economia, Administração e Sociologia Rural - SOBER, 2010. Campo Grande. Anais ...Campo Grande: SOBER, 2010, p.1-17.

VENEGAS, J.A.G. Caracterización e tipificación de sistemas productivos de leche em La Décima Región de Chile: um análisis 
multivariable. 2007. 104 p. Monografia (Graduação). Universidad Austral de Chile. Facultad de Ciencias Agrarias - Escuela de Ingeniería em Alimentos. Valdivia, Chile, 2006.

\section{ANEXO}

Tabela A1. Tecnologias e variáveis utilizadas para o cálculo do Índice de Desenvolvimento Tecnológico Global (IT).

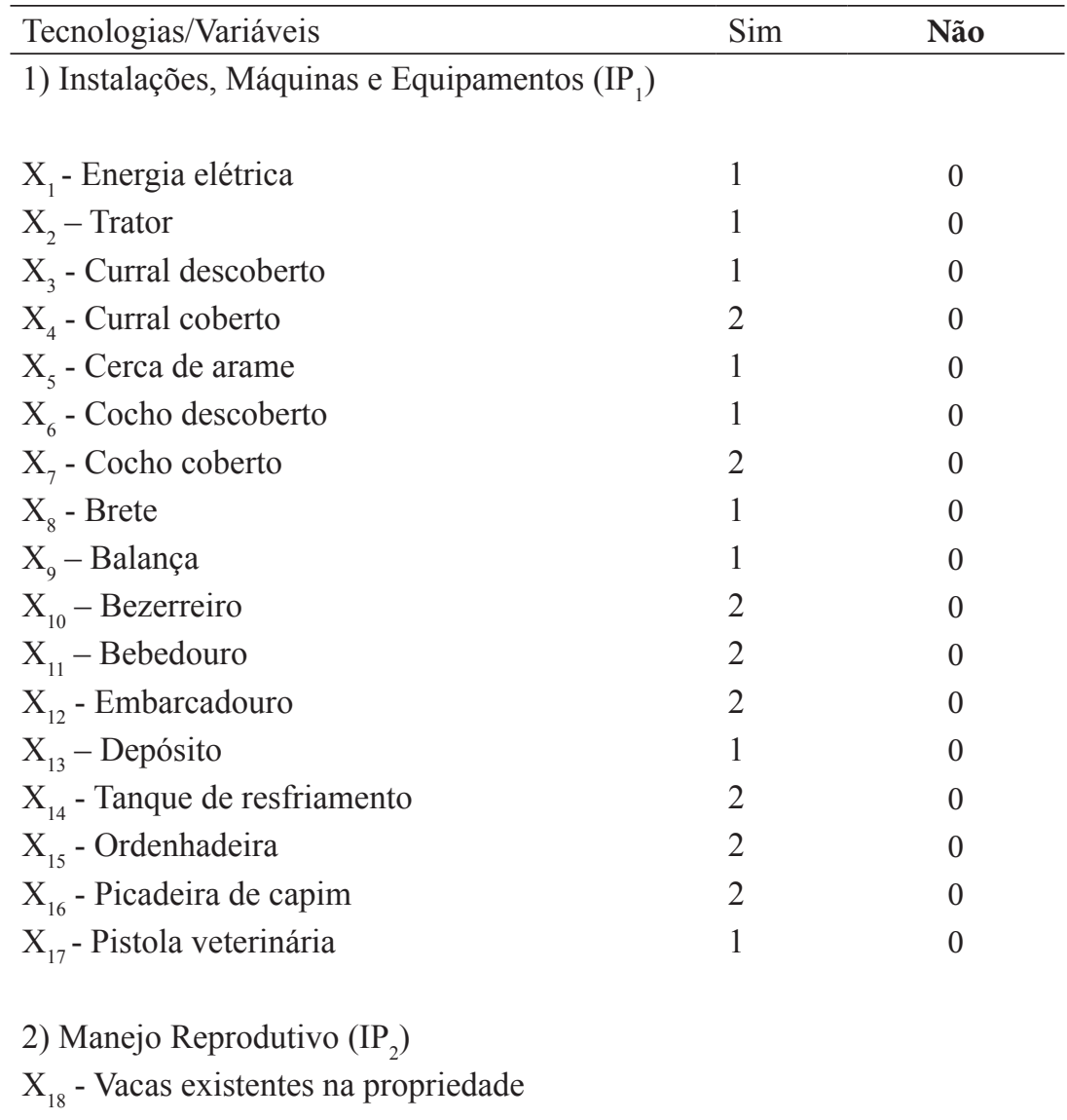


Vacas leiteiras

Vacas de corte

Vacas mestiças

$\mathrm{X}_{19}$ - Touros existentes na propriedade

Touros de leite

Touros de corte

Touros mestiços

$\mathrm{X}_{20}$ - Sistema de acasalamento

-Monta natural

-Monta controlada

-Inseminação artificial

$\mathrm{X}_{21}$ - Objetivos dos acasalamentos

-Produção de leite

-Produção de carne

-Dupla aptidão

$\mathrm{X}_{22}$ - Critérios para a primeira cobertura

-Natural/Não controla

-Peso

-Idade

$X_{23}$ - Utiliza estação de monta

$\mathrm{X}_{24}$ - Realização de exame reprodutivo nos touros 2

3) Manejo Sanitário $\left(\mathrm{IP}_{3}\right)$

$\mathrm{X}_{25}$ - Vacinações realizadas

-Aftosa

-Brucelose

-Manqueira

$\mathrm{X}_{26}$ - Realização de vermifugação

$\mathrm{X}_{27}$ - Realiza corte e desinfecção do umbigo

$\mathrm{X}_{28}$ - Realiza algum exame sanitário no rebanho

$\mathrm{X}_{29}$ - Fornece colostro aos bezerros

$\mathrm{X}_{30}$ - Tipo de ordenha

-Manual tradicional 
-Manual higiênica 1

-Ordenha mecânica 2

$\mathrm{X}_{31}$ - Realiza diagnóstico de gestação 2

$\mathrm{X}_{32}$ - Sistema de pastejo

-Contínuo

-Alternado

-Rotacionado

$\mathrm{X}_{33}$ - Método usado no controle de invasoras

Roçagem manual

Roçagem e queima

Herbicida

Roçagem mecânica

$\mathrm{X}_{34}$ - Não usa fogo no pasto

$X_{35}$ - Já fez reforma de pastagens

$\mathrm{X}_{36}$ - Utiliza fertilizante químico nas pastagens

$\mathrm{X}_{37}$ - Cultiva leguminosas para a alimentação dos animais

$\mathrm{X}_{38}$ - Realiza análise de solos

$\mathrm{X}_{39}$ - Possui capineira na propriedade

$\mathrm{X}_{40}$ - Fornece suplementação alimentar para o gado 1

$\mathrm{X}_{41}$ - Fornece sal mineral diariamente

5) Gestão e Planejamento da Produção $\left(\mathrm{IP}_{5}\right)$

$\mathrm{X}_{42}$ - Recebeu financiamento

$\mathrm{X}_{43}$ - Pretende investir na produção de leite 2

$\mathrm{X}_{44}$ - Realiza anotações de dados sobre o rebanho

$\mathrm{X}_{45}$ - Possui assistência técnica regular 2

$\mathrm{X}_{46}$ - Participou de algum treinamento/capacitação 2

$\mathrm{X}_{47}-$ Tempo de estudo

-Menos de 5 anos

-De 5 anos a menos de 10 anos 
Ana Laura dos Santos Sena, Marcos Antônio Souza dos Santos, Jair Carvalho dos Santos \& Alfredo Kingo Oyama Homma

$\mathrm{X}_{48}-$ Experiência na atividade

-Menos de 5 anos

$0 \quad 0$

-De 5 anos a menos de 10 anos

$1 \quad 0$

-De 10 anos a menos de 20 anos

20

-20 anos e mais

30

$\mathrm{X}_{49}$ - Mão de obra ocupada

-Familiares

$0 \quad 0$

-Trabalhadores permanentes

$2 \quad 0$

-Trabalhadores temporários

$1 \quad 0$

$\mathrm{X}_{50}$ - Utilização de técnica inovadora $\quad 2 \quad 0$

$\mathrm{X}_{51}$ - Realiza resfriamento do leite após a ordenha 220 
REVISTA DE ECONOMIA E AGRONEGÓCIO, VOL.10, $N^{\circ} 3$ 